This item was submitted to Loughborough's Research Repository by the author.

Items in Figshare are protected by copyright, with all rights reserved, unless otherwise indicated.

\title{
Safety in numbers: mathematics support centres and their derivatives as social learning spaces
}

\section{PLEASE CITE THE PUBLISHED VERSION}

http://dx.doi.org/10.1080/03075070903078712

\section{PUBLISHER}

Routledge (@ Society for Research into Higher Education)

VERSION

AM (Accepted Manuscript)

LICENCE

CC BY-NC-ND 4.0

\section{REPOSITORY RECORD}

Solomon, Yvette, Tony Croft, and Duncan Lawson. 2019. "Safety in Numbers: Mathematics Support Centres and Their Derivatives as Social Learning Spaces”. figshare. https://hdl.handle.net/2134/8629. 
This item was submitted to Loughborough's Institutional Repository (https://dspace.lboro.ac.uk/) by the author and is made available under the following Creative Commons Licence conditions.

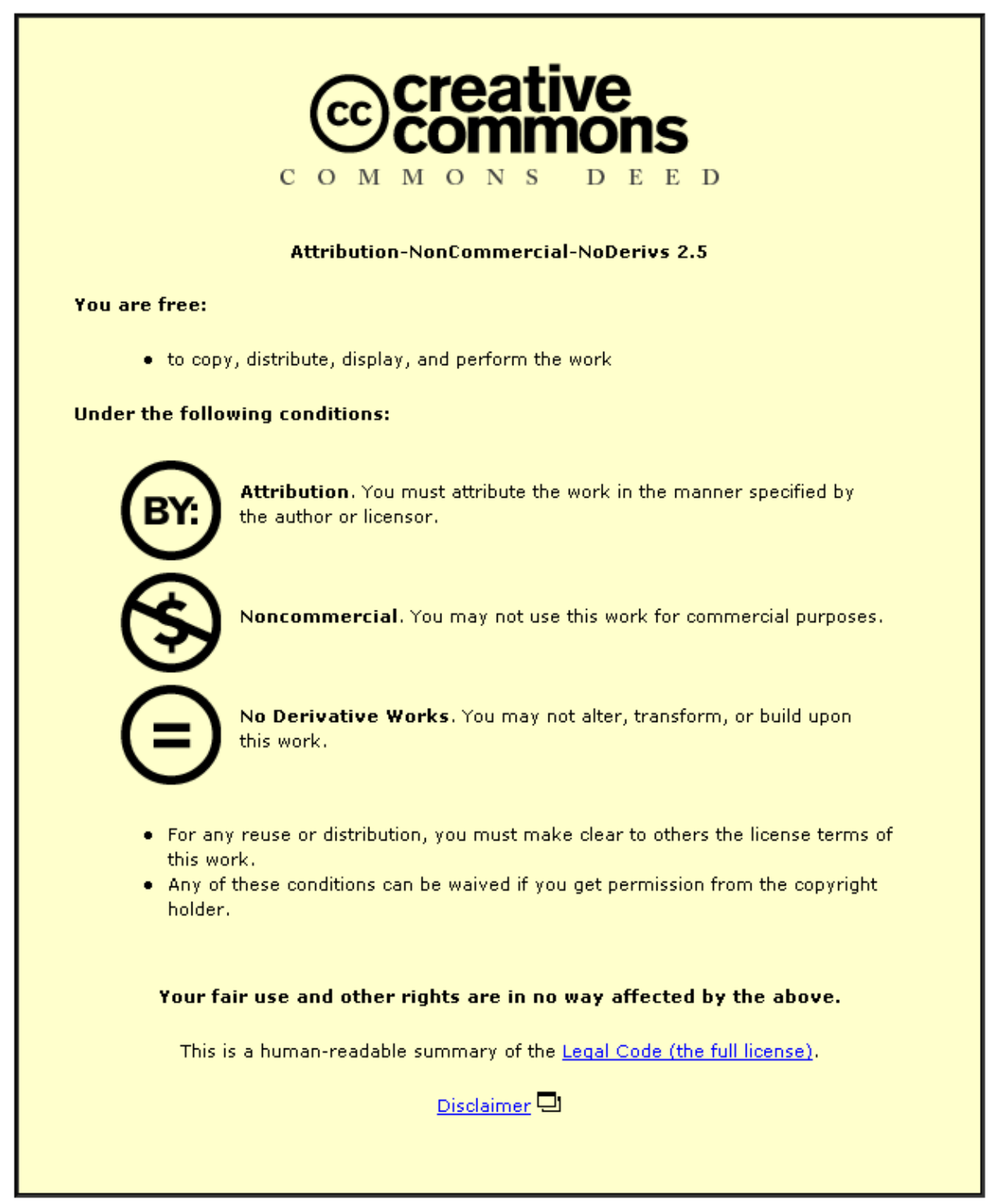

For the full text of this licence, please go to: http://creativecommons.org/licenses/by-nc-nd/2.5/ 
Safety in numbers: mathematics support centres and their derivatives as social learning spaces

Yvette Solomon $^{1}$, Tony Croft ${ }^{2} \&$ Duncan Lawson ${ }^{3}$

${ }^{1}$ Department of Educational Research, Lancaster University, Lancaster, UK

${ }^{2}$ Mathematics Education Centre, Loughborough University, Loughborough, UK

${ }^{3}$ SIGMA, Faculty of Engineering \& Computing, Coventry University, Coventry, UK

${ }^{1}$ Corresponding author: Yvette Solomon, Email y.solomon@lancaster.ac.uk 


\section{Abstract}

This paper reports on data gathered from second and third year mathematics undergraduates at two British universities which have developed Mathematics Support Centres, primarily with a view to supporting skills development for engineering students. However, an unforeseen consequence of the Support Centres was the mathematics students' colonisation of the physical space and the development of group learning strategies which involve a strong community identity. Drawing on a socio-cultural theoretical framework based primarily in the concept of a figured world, we explore the students' perceptions of mathematics learning and their experiences of university level teaching, focusing on the ways in which they collectively build images of themselves as participants in an undergraduate mathematics community, resourced by the physical safe spaces that they have created, and which they now regard as essential sites of their learning.

\section{Identity and community in the undergraduate experience}

Transition to university involves academic challenges for the majority of students, but the move to undergraduate mathematics appears to present particular hurdles: a number of studies report a strong pattern of difficulty and disengagement in both pure and applied degrees (Brown \& Macrae, 2005, Hawkes \& Savage, 2000), and high levels of switching/drop-out (Seymour \& Hewitt, 1997). In the UK this is primarily considered to be the result of changes in the A-level curriculum and hence lack of preparation (Hoyles et al., 2001, Lawson, 1997, Macrae et al., 2003, Perkin et al., 2007, Smith, 2004), but research indicates that contextual factors relating to 
adjustment to university study are equally important: for example, Brown \& Macrae (2005) found that students who had more positive attitudes to studying mathematics shared ideas in a mathematical community, while Seymour \& Hewitt (1997) identified students’ mutual tutoring and support as a major factor in continued participation in science/mathematics degree programmes. A focus on undergraduate learning communities thus shifts attribution of the problem from students’ knowledge/skills deficits to teaching and learning contexts.

Here we report in detail on the development of student learning communities in two universities, where supporting strategies initially aimed at skills development for engineering students provided the impetus and resources for the generation of a mathematics undergraduate community of practice (Wenger, 1998) in which collaborative working is a key characteristic. We will suggest that an analysis of the students' accounts provides an insight into the undergraduate mathematics experience which goes beyond a skills deficit model. Specifically, it suggests that a central issue in adjustment to university mathematics is the nature of relationships with tutors and peers; in our study this issue finds a focus in the availability of physical spaces for learning which enable a collective refiguring (Holland et al., 1998) of student and tutor roles.

Two major studies provide the background for this paper: the UK-based Student Experiences of University Mathematics (SEUM) project (see Brown \& Macrae, 2005), and Seymour and Hewitt's (1997) study of switching and drop-out in Science, Mathematics and Engineering (SME) programmes at seven US four-year colleges and universities. Both of these studies suggest, in different ways, that peer-group relations 
play an important role in success. An important finding of the SEUM project, which tracked undergraduate mathematics students for three years in two British universities, was the impact of the student/tutor community (or lack of it) on how students experienced university study. In one institution, this community focused on a particular physical space which comprised informal work/social/eating areas and adjacent staff offices, with the result that "students could 'catch' lecturers going to and from these offices, as well as make formal and informal appointments to discuss various concerns” (Brown \& Macrae, 2005, p.6). In contrast, the other university contained a high proportion of commuting students who lived at home, and a lack of social space in the institution itself. Brown and Macrae report that students felt isolated, had difficulty making friends, contacted lecturers less, and showed lower attendance at some lectures. Related issues concern engagement with the community in general - students who were active participants in lectures/tutorials, or became involved in society or mentoring activities were more confident. More importantly for the present study, students who worked together or lived with other successful students were themselves more likely to be successful. In one institution, small team project work in the first year was welcomed because it "enabled them to learn from each other and become socially more cohesive” (Brown \& Macrae, 2005, p.7). Students generally appreciated project work not just because it was collaborative but also because it allowed them to work at their own pace.

Seymour and Hewitt’s (1997) large-scale ethnographic study identifies similar issues with respect to the role of collaborative learning as a component of student survival in SME subjects, in which mathematics and statistics are the most vulnerable to student movement to other subjects (p.16). They found that many students, whether or not 
they dropped out or switched programmes, tended to report the transition to university as challenging in terms of pace, workload and teaching methods - issues reported by students in the SEUM project as well. Over one third of switchers cited 'poor teaching' as a reason for switching, but it was also cited as a concern by nearly three quarters of non-switchers. In a similar pattern, inadequate academic and pastoral support was given as a reason for switching in one quarter of the students, but was also a concern for more than a half of the non-switchers. While it might be argued that switching is the result of inadequate school preparation, and indeed was cited as a reason for leaving by $15 \%$ of switchers, it was also mentioned by $38 \%$ of nonswitchers as a concern. Conceptual difficulties were cited as a concern by one quarter of the students in both groups. Thus there is scant evidence that switching is a result of the 'hardness' of SME subjects alone, and, like the SEUM students, those in Seymour and Hewitt's study differed in terms of whether or not they had sufficient resources to continue in terms of a feeling of belonging to the undergraduate community. One such resource is peer study support: lack of it was given as a reason for leaving or as a concern by 39\% of switchers, compared to $7 \%$ of non-switchers. Crucially, its benefits extended beyond day-to-day survival to a more participative identity:

Both switchers and non-switchers described the unique educational benefits of collaborative learning which took them far beyond what was possible in class work alone. These included: reinforcement of understanding and skills; learning at a deeper level; learning by teaching; generation of new ideas and applications; personal intellectual challenge and growth; willingness to share mistakes and learn from them; pleasure in debating intellectual issues; and discovering the enjoyment of learning. (Seymour \& Hewitt, p.174) 
Together with earlier research (Solomon, 2007, Solomon, 2008) which suggests the importance of self-positioning in the undergraduate mathematics community of practice, these studies indicate the value of understanding the impact of dedicated mathematics support centres on student identities and approaches to learning. The establishment of such support centres represents one way in which many British universities have responded to the challenges mathematics educators face at the school/university transition - challenges which have been articulated in the Post-14 Mathematics Inquiry’s conclusion that "higher education has little option but to accommodate to the students emerging from the current GCE [ie pre-university schooling] process” (Smith, 2004, Section 4.39, p.95). In general, support centres offer a facility to students, not necessarily of mathematics, which is in addition to their regular programme of teaching through lectures, tutorials, problem classes and personal tutorials. While their greatest benefit is the availability of focused one-to-one support as an immediate response to specific problems, students also comment on the importance of atmosphere and the learning environment, an increase in student control and lack of time pressure, and the informality and psychological security of centres (Lawson et al., 2001).

A support centre requires a physical location from which to operate. Usually this is either within a teaching department or within a central facility such as a library or learning resources centre. At institutions where the centre is open for most of the week it is common practice to have dedicated space for the purpose and, as we shall show, it is this factor which is particularly pertinent to the development of undergraduate communities of practice. In this paper we draw on Holland et al's (1998) concept of a figured world to provide the framework for an exploration of the 
ways in which students position themselves, each other, and their tutors in relation to learning mathematics, and the role of physical space in their shifting identities. The figured world is 'a socially and culturally constructed realm of interpretation in which particular characters and actors are recognized, significance is assigned to certain acts, and particular outcomes are valued over others' (p. 52); as a way of describing the community of mathematics students and their tutors, it enables the researcher to identify the range of roles that are enacted in the community, and, of particular interest here, 'the day-to-day and on-the-ground relations of power, deference, and entitlement, social affiliation and distance' (pp. 127-128). Power is important in any teaching and learning context, but it appears to take special significance in the mathematics world where lecturers are frequently positioned as undisputed authority figures (de Corte et al., 2002, Schoenfeld, 1992). However, in Holland et al’s framework, it is possible to effect a change in power relations through reflection on the nature of the figured world itself:

The everyday aspects of lived identities ... may be relatively unremarked, unfigured, out of awareness, and so unavailable as a tool for affecting one's own behavior. ... [But] Ruptures of the taken-for-granted can remove these aspects of positional identities from automatic performance and recognition to commentary and re-cognition. (pp.140-141)

Reflection and hence re-figuring can also take place on the level of the collective:

This disruption happens on the collective level as well. Some signs of relational identity become objectified, and thus available to reflection and comment.... Alternative figurings may be available for interpreting the everyday, and alternative ways of figuring systems of privilege may be developed in contestations over social arrangements. (pp.141-2) 
In this paper, we examine the dynamics of a collective refiguring of relations and identities within two particular mathematics communities, and the ways in which students draw on the presence and use of physical space as a resource to change their relationships with their subject.

\section{The study}

The data on which this paper is based are drawn from focus groups involving 21 mathematics students in their $2^{\text {nd }} / 3^{\text {rd }}$ years, attending 2 different universities in England - Farnden and Middleton (pseudonyms) - which both have long-standing, well-established and well-resourced support centres. It is noteworthy that the two centres were originally set up with an emphasis on dealing with mathematics for engineering undergraduates; however, mathematics undergraduates were also entitled to use the centres and in fact increasingly did so. This group of students were invited to participate in the focus groups reported here. All were known to make good use of the Mathematics Support Centres; nineteen (12 men and 7 women) were taking single majors in mathematics, and two (both women) were studying joint degrees with statistics or accounting. The students participated in 6 focus groups in which they were asked to discuss their experiences of learning mathematics at university. Three of the students at Farnden participated twice - in their second year and again one year later. In addition, $382^{\text {nd }}$ year students at Middleton completed survey questionnaires covering various aspects of their experience of learning mathematics at school and at university, their attitudes to mathematics and their approach to learning. Focus groups were fully transcribed and analysed thematically with particular focus on issues of changes in the experience of teaching and learning, the development of 
independence, relationships with tutors and tutor support, individual and group working practices, and the use of space. All student names in this paper are pseudonyms.

\section{Stepping up and becoming independent: moving through university mathematics}

Our analysis in this paper focuses on the qualitative data and the students' accounts of their learning communities and their use of space, but particular issues identified in the survey data provide an overall context which we report briefly first. Of greatest importance here is the transition from school to university mathematics in terms of changes in perceptions and learning experiences. Looking back at school, 46\% agreed that "maths was more fun at school" and 90\% agreed that "before I came to university maths was one of my favourite subjects”. It was also a subject at which students did well: 92\% agreed that "before I came to university maths was one of my best subjects" and for $80 \%$ "I was better at mathematics than most other students in my class”. However, once at university the reference group against which academic self-concept is measured changes (cf Marsh, 1987): 26\% agreed that since coming to university, "I realise that I am not very good at maths" and 31\% agreed that "most mathematics students are cleverer than I am”. For some, this appears to lead to a loss of confidence: $23 \%$ disagreed with the statement that "my university experience has resulted in me being more confident with mathematics”. Asked about the teaching at university, $47 \%$ disagreed that "the style of university teaching suits my learning style” and $46 \%$ disagreed that "maths is taught better at university”. These findings reflect those of the research reviewed above, particularly with respect to the transition from school and a shift in the experience of mathematics learning from ease to 
difficulty for one quarter of the students, and a dissatisfaction with teaching style at university for half of them. These changes in the students' experience play an important part in their ongoing relationships with mathematics and their use of the support centres and of each other as a means of coping with 'stepping up'; these issues are fleshed out in our analysis of the focus group data which follows.

Looking back on their first year, second year students described the course as significantly more difficult, compounded by greater speed of delivery, as Roz (Farnden Year 2) describes:

There is a big step up in the complexity of what we are being taught and the speed at which we are being taught to absorb it and get to grips with it. ... because it's a lot more complicated, the work takes longer and you can't afford not to do it.

The volume of work also changes: Farnden Year 2 student Eladio comments that it was all a bit of a shock:

The context of our study has been 3 times more difficult than the first year. ..... It was a shock in fact. .... I'm doing about 50 hours a week and that still is not enough.

Indeed, upon reaching Year 3, Roz says that 'It seems to get more difficult exponentially'. These changes have an impact on the way that students engage with the material: they describe writing notes in lectures without understanding, thinking the material through on their own, afterwards, or in the group:

Rachel (Farnden Year 3): ... I'd rather go home and read it myself and then work through the questions, because the first time round I don't even know 
what he’s talking about most of the time because I can't read it and listen, I have to just write because I have to keep up with it.

In addition to the increase in conceptual difficulty and pace there is another issue, also observed in the SEUM study: this is the students’ perception that they need to develop a certain level of independence as they progress, and that tutors correspondingly withdraw support. Covering the curriculum in class means less time spent on going over homework problem sheets and hence a greater requirement that students work on their own, explained here by Adam and Liam (Farnden Year 2):

Adam: In the first year .... there was a lecture and then we did questions but I think now because we're in year 2 we're expected to do questions in our own time so the lecturer is not wasting time... he's teaching us as much as he can because I guess the syllabus has to go through so much that he has to spend the lecturing time talking..

Liam: Because when we're supposed to do a tutorial and we have exercises to go through, that won't necessarily cover everything that we will come across in exams and coursework. It just gives you a basic understanding where you will have to research more after that to be able to grasp the whole concept.

Withdrawal of support troubled some students, who reported needing constant reassurance that they were on the right track. Thus Alice (Farnden Year 2) says that getting constant feedback is a must: 'I like getting the answers ... you need the feedback'. Matt and Tim (Middleton Year 2) added to this the need to be pushed in order to work:

Tim: Last year I felt I was working a lot harder. In the first year we had 2 or 3 pieces a week at least ...

Matt: And we had more tests as well. 
Tim: ... .whereas this year it's a lot more independent and you've got nothing to force you.

In Year 3, projects demand different kinds of independence, including the ability to sustain work over a long period of time and without immediate feedback. At Middleton, Year 2 student Megan is anxious that she will not be able to manage her time properly:

What's next year going to be like? Panic. Why? I've got to do a final year project. What's the scary thing? It sounds like it's going to involve a lot of work over a long period of time and I'm not very good at pacing myself and making myself do work that's not due in immediately.

Liz and Rachel have already started their projects, but feel insecure:

Rachel: In an ordinary course with homeworks we tend to get given answers so that we know that we're going in the right direction, but in this we're not, we’re just told ‘do it’ - I don’t know if we're going to get given the answers....

Liz: .... you could be there for a whole 2 months doing questions and you don't know.

Rachel: ...We still don't know if we've got the right answers, and that's scary just purely because we could be going off on a complete tangent and we'll never know.

Although they recognize that they are supposed to develop greater independence in the third year, Liz and Rachel say that they have not particularly adapted to this requirement - rather, they simply feel more pressurized. 


\section{Safety in numbers: moves towards a collective refiguring}

One way in which students at both Farnden and Midldleton cope with these changes is through greater use of the support centres, with two main effects: a shift in relationships with tutors, and the development of group learning strategies. Roz, in Year 2 at Farnden, reflects on the first of these:

When they are in maths support, you know they're there to help people and you're not bothering them. If you go to their office, you've got your stuff in your bag, there's nowhere to get it out to show them, you know there's a queue of people behind you, they were doing something before you arrived if there wasn't anyone in the queue ahead of you so you feel like you're bothering them, it's their space as well and you're going into their office, whereas maths support is neutral ground for everybody ... it doesn’t belong to anybody, you've got your stuff out and they will work their way round the table to come to you, you have your work out ready even if you've put it to one side so you can flip back to it and say “can you just help me with this”.

While this refiguring of the tutor-student relationship is clearly crucial, a related and equally important effect of the support centres is on the students' general approach to learning, and their positioning of each other as engaged participants in their local community of practice. Partly, this occurs as a result of the pressures that they are under; the Farnden students explained how in their second year they had become more cohesive as a group:

Liam: There's a lot of interaction between the subgroups. (So what's changed? What's made that difference?) .... I think because the workload, because it's got harder, because it's a lot more difficult to do it on your own kind of forces bonds to be created between people in the same group. 
Given that many lectures are fast, difficult to follow, and allow little - if any - time for discussion, while tutorials are risky spaces because many students feel exposed if they ask questions, working informally with peers outside of timetabled contact time is the only opportunity to talk about their work. One of the benefits is getting explanations from angles other than the lecturer's:

Rachel: If you don't understand it they can explain it to you more on your level rather than the way the lecturer would so they help you to understand it if they do - that's why [the support centre] is so helpful, because you can sit next to people at the round tables and you can explain things in a way that makes sense to you.

Working together can have benefits for both parties, as Jess (Middleton Year 2) and Hugh (Farnden Year 2) explain:

Jess: It's sometimes if there's two of you and you're both struggling but you've both got half of the answer then you work together you can put your half answers together and get the right answer.

Hugh: A big advantage of the Maths Support Centre is that you can get anyone going in there from any course and they might come in with some weird problem which you know how to do but you wouldn't think of looking at it that way or what they've been shown, so it could give you a different way of looking at a problem and potentially help you understand it better.

The benefits extend beyond helping each other with specific problems, however. Working together enables greater ownership of knowledge, and a more participant identity which is also displayed in their use of virtual space:

Roz: Sometimes we use the message board as well to exchange information relevant to the module if there's a piece of information that's relevant for a 
piece of coursework or that's relevant to everybody, we'll put it up on the message board and have a discussion about it.

Talking one year later, Caitlin explains how even individual project work can be part of working in the group:

I think a lot of the work is more individual now because we've all got a project ... so sometimes you find that you're working on your own, but you still bounce ideas off other people.

Roz sums up the changes in terms of the elusive third year independence:

But because we've worked so well together beforehand I know that if I get stuck I can ask them and if they get stuck they can ask me even if we're not working at the same time. In that sense there's more independence....

\section{Defining community spaces}

Although there were limits to how much help from tutors they could receive in the learning support centres - which had, as we have noted, been set up with other students in mind - the undergraduate mathematics students at both Farnden and Middleton had continued to use these as spaces for group study. Roz explained how things had developed:

... towards the end of the first year, ... I used it a lot because a group of us who tend to get fairly good marks used it a lot. Other people sort of came in to work with us and got the help and so on and so....we got...we feel that we kind of established it in some way by using it a lot and encouraging other people to say “well we'll meet in the Maths Support Centre and we'll work together” sort of thing. And then......and it developed a real upspin, it was 
really kind of in a sense the place to be, and there was a lot of people, there was a lot of use ....

This account is corroborated by other Farnden year 2 students, who report that use of the centre has increased, now catering for around two thirds of the second year - Liam comments that “we're all just flocking to the Maths Support Centre”. The importance of the physical space itself is illustrated by events at Farnden, where the unanticipated popularity of the support centre among mathematics students has caused overcrowding and a decision to limit access for the second and third year students in order to enable the centre to cater for its original target of first year students and nonmathematicians. Although they have been provided with an alternative room, the changes have had far-reaching effects. Roz, Tamsin and Caitlin tell the story of how some students are complying with the request to use the new room, whereas others are not. The effect is disruption to what had been a strong collaborative working system based on ownership and collective action:

Roz: You need to appreciate as well that ....I mean, it becomes ours when we use it in that sense. The most important thing for me is (a) to have a space to work (b) to have these guys around. ....

Caitlin: I think the atmosphere in that room is not as good because some people choose to work elsewhere, so.....

Roz: [It] Disrupted the group....working in Maths Support.

Caitlin: Yeah, we haven't got the same help group as we had. Because we're all better at different aspects of the work and now we've found that there's not as many of us there so you haven't got as many points of view I don’t think. 
The room layout itself was also important - the new room they had been provided with lacked the round tables of the original support centre, and so it was more difficult to work together, with far-reaching consequences:

Roz: You work with your back to each other.

Tamsin: We've had a couple of Fridays where we've worked at home just because we thought "well....no point going in", whereas we never did that because Maths Support was just such a nice space to work in.

Roz: There's also the issue that some people still use Maths Support and some people go to the new room, so it was kind of polarised in a sense.

Tamsin: Some’s left....

They go on to describe how some students now visit the group only when they need help. This erosion of their collaborative practice is important: although Roz is clearly positioned as a student authority and a source of help, she emphasises once again the value of other students' contributions:

Roz: The thing is if we started a project we'd work together and we would talk round the questions. Everyone has something to offer, even if it's a perspective that happens to be wrong, because then we could discuss their idea.

\section{Conclusion: refiguring identity spaces}

This account of how students first used the space provided by the support centres because they needed to, but then began to take ownership of their own learning and to refigure not only their relationships with their tutors but with doing mathematics itself, provides an explanation for the central role of peer group support observed in the research reviewed at the beginning of this paper. It also provides an insight into 
how an undergraduate community of practice, which can be highly competitive and individualistic, generating identities of not belonging among students (see Solomon, 2007), can refigure itself into something very different, drawing on physical space as a major resource. Holland et al (1998) suggest that while individuals develop relational identities in terms of dispositions to act in particular ways, these can be 'disrupted' when reflection enables recognition of positional identities which may then be objectified and challenged, and so lead to refiguring:

The same semiotic mediators, adopted by people to guide their behaviour, that may serve to reproduce structures of privilege and the identities, dominant and subordinate, defined within them, may also work as a potential for liberation from the social environment. .... When individuals learn about figured worlds and come, in some sense, to identify themselves in those worlds, their participation may include reactions to the treatment they have received as occupants of the positions figured by the worlds. (Holland et al 1998, p.143)

Thus we can see Roz in particular as a student who objectifies the lecturer-student relationship in her account of the shift in power dynamics which the support centre affords. What is most notable here, however, is the collective refiguring by the Farnden and Middleton students which counters the dominant view that mathematics is an isolated pursuit. This shift shows similarities with Boaler and Staples' (2008) findings on relational 'multidimensional classrooms' - classrooms in which multiple methods and solutions were valued and students took responsibility for each other's learning. The Middleton and Farnden students appear to collaborate across 'abilities', and their ethos in practice tends towards a recognition that everyone has different perspectives and understandings. As these Year 2 Middleton students describe, working together has become central to their practice: 
How much difference does working together make?

Nick and Megan: A lot.

Yu: I think most of the learning is done through helping each other, everyone's got their strength and weakness....

Megan: Yes, working through things.....and if you head off on the wrong way to start with you get help ...

You're saying that the major part of your learning is working together?

Megan: Yes.

These data show the value of providing space for students to develop their own communities of practice, demonstrating that for many of them, learning mathematics can be a social experience and one that they would prefer to do as a group. As a subject which is popularly seen as highly individualistic (Schoenfeld, 1992), this refiguring of students' ways of relating to mathematics and to their tutors is particularly significant and suggests that the provision of space for social learning may be similarly important in other, less ‘individual’ subject areas. This is not to say that this is a solution for all students: we should recognise that these particular participants have chosen to colonise the space, and they are not typical of all the students in their cohorts. In the Middleton questionnaire the group was split, with $46 \%$ agreeing that they prefer to do mathematics on their own and 51\% preferring to work within a group. However, for many students a quality learning experience includes the provision of spaces and resources within those spaces which facilitate student interaction and peer support, as Roz argues:

... we all enjoy collaborative working ... I think we've all done better, well I've certainly done a lot better than I would have done if we hadn't had each other. 


\section{References}

Boaler, J. \& Staples, M. (2008) Creating mathematical futures through an equitable teaching approach: The case of Railside school. Teachers' College Record, 110(3), 608-645.

Brown, M. \& Macrae, S. (2005) Students' experiences of undergraduate mathematics Final report to the Economic and Social Research Council.

De Corte, E., Op’t Eynde, P. \& Verschaffel, L. (2002) "Knowing what to believe”: The relevance of students' mathematical beliefs for mathematics education, in: B. Hofer \& P. Pintrich (Eds) Personal epistemology: The psychology of beliefs about knowledge and knowing (Mahwah, N.J, Lawrence Erlbaum).

Hawkes, T. \& Savage, M. (Eds.) (2000) Measuring the mathematics problem, (London, Engineering Council).

Holland, D., Lachicotte Jr, W., Skinner, D. \& Cain, C. (1998) Identity and agency in cultural worlds, (Cambridge, Massachusetts, Harvard University Press).

Hoyles, C., Newman, K. \& Noss, R. (2001) Changing patterns of transition from school to university mathematics. International Journal of Mathematical Education in Science and Technology, 32(6), 829-845.

Lawson, D. (1997) What can we expect of a level mathematics students? Teaching Mathematics and its Applications, 16 151-156.

Lawson, D., Halpin, M. \& Croft, T. (2001) After the diagnostic test - what next? . MSOR Connections, 1(3), 19-23.

Macrae, S., Brown, M., Bartholomew, H. \& Rodd, M. (2003) The tale of the tail: An investigation of failing single honours mathematics students in one university 
in: J. Williams (Ed.) Proceedings of the British Society for Research into Learning Mathematics. 23 (2), Oxford, 55-60.

Marsh, H. (1987) The big-fish-little-pond effect on academic self-concept. Journal of Educational Psychology, 79(3), 280-298.

Perkin, G., Pell, G. \& Croft, T. (2007) The mathematics learning support centre at loughborough university: Staff and student perceptions of mathematical difficulties. Engineering Education, 2(1), 47-58.

Schoenfeld, A. (1992) Learning to think mathematically: Problem-solving, metacognition and sense making in mathematics, in: D. A. Grouws (Ed.) Handbook of research on mathematics teaching and learning. New York, Macmillan), 334-370.

Seymour, E. \& Hewitt, N. (1997) Talking about leaving: Why undergraduates leave the sciences (Boulder, CO., Westview Press ).

Smith, A. (2004) Making mathematics count - the report of professor Adrian Smith's inquiry into post-14 mathematics education. Report for DfES (London).

Solomon, Y. (2007) Not belonging? What makes a functional learner identity in the undergraduate mathematics community of practice?' Studies in Higher Education, 32(1), 79-96.

Solomon, Y. (2008) Mathematical literacy: Developing identities of inclusion, (New York \& London, Routledge).

Wenger, E. (1998) Communities of practice: Learning, meaning and identity, (Cambridge, Cambridge University Press).

5,538 words 